\title{
A Multidimensional Analysis of Socioeconomic Factors in Housing Policy in the Eurozone Countries (2010-2014)
}

\author{
António Duarte Santos ${ }^{1}$, Nelson Tavares da Silva ${ }^{2}$, Guilherme Castela ${ }^{2}$
}

${ }^{1}$ CIEO - Research Centre for Spatial and Organizational Dynamics, Autonoma University of Lisbon, 1150-293 Lisbon, Portugal, e-mail: ajsantos@autonoma.pt

${ }^{2} \mathrm{CIEO}$ - Research Centre for Spatial and Organizational Dynamics, University of Algarve, Campus de Gambelas, 8005-139 Faro, Portugal, e-mail: info@ntavaresdasilva.com, e-mail: gcastela@ualg.pt

\section{SUMMARY}

The latest global economic and financial crisis has had adverse social consequences in many areas, including income and the social situation of households and their living conditions, especially when the housing phenomenon is addressed. The reality of this uncertainty has made the study of the housing phenomenon even more relevant, in particular from the perspective of an analysis of its evolution. In this context, we revisit EUROSTAT's databases. This analysis was done for twelve Euro Area countries over five years, using the HJ-BIPLOT method developed by Galindo (1986). This multidimensional approach identified and represented twelve Eurozone sample countries in latent constructs of reduced dimensionality related to the housing policy problem. The simultaneous factorial representation identified (a) the most relevant variables to characterize these countries, (b) their trajectories during the period in analysis, and (c) the relations between variables, between countries, and between variables and countries. This approach also identified the most significant factors contributing to the countries' performance. This methodological approach can be useful in housing research, when studying data of a multivariate nature, and is also, by its visual interpretation, a potential tool for producing richer information not only for academia but also for policy makers.

Key words: housing policy, housing affordability, BIPLOT

\section{Introduction}

Since the beginning of the mortgage crisis in the United States in 2007, with its origins in the collapse of the sub-prime mortgage boom and housing prices bubble (MARTIN, 2011), and after the financial crisis in the European Union and Eurozone countries in 2008, there has been growing concern about the housing issue. This concern has been focused on the framework of public policy, which 
has made changes and adaptations and has specific characteristics for the behaviour of housing demand. Given the growth of housing affordability problems, the decrease in disposable income, the reorganization of households' behaviour and their adjustment to a new social and economic paradigm, this concern still persists. It has therefore become essential to recognize the institutional intervention of economic operators in the market, in particular from the state, owners and households (NEWMANN et al., 2000; DEWILDE et al., 2015; HAFFNER et al., 2011).

In the period 2010-2014, the state played an on-the-go role in the housing sector, legislating and promoting the purchase of housing owning and renting. Indeed, from early in the decade, and up to 2014, concerns of a more social nature were added to these housing policy guidelines, and rehousing programmes were created in urban areas, with support for leasing with incentives particularly for young people and stimulus for the recovery of degraded properties. The purchase of homes by households, house renting on the open market - and specifically by young people - pushed the state forward as a stimulating element in the housing market and urban regeneration, theoretically through an equity-based redistribution of income for households (ANDREWS et al., 2011).

However, the problem of housing cannot be reduced only to a perspective of supply and demand. In fact, the specific characteristics of this problem led to the creation of inefficiencies in the market, in particular due to the inadequacy of market argument as a resolution mechanism for housing in lower-income households. The strengthening of housing programmes for the most insolvent populations had the effect of partially solving housing needs, but it was not enough (SANTOS, 2014). In the general European case (DEWILDE, 2016), the housing reality was mainly constructed by the acquisition of one's own housing, given the comparative low expression of the rental market. Nonetheless, it only provided a housing solution for relatively solvent households. Consequently, in this period, the housing credit supply matured, interest rates had a significant downward trend, access to credit for households stabilized, and new opportunities arose for the financial institutions (ARESTIS et al., 2013). 
Therefore, a new relative extension of housing credit and a fresh attitude towards the rental alternative in these years was a rational response of economic agents to favourable changes in financing conditions, and not only in southern European countries. On the other hand, the development of a more dynamic rental market was another goal of housing policies in this period.

We take it as relevant to characterize the Eurozone countries, on a housing policy perspective and in a post-crisis context, incorporating ten variables considered to be the most pertinent, based on data from Eurostat. We used five groups of indicators: general economics, housing stocks, housing affordability, population and social conditions, and housing quality (EUROSTAT, 2014), to relate WEALTH and LIVING STANDARDS with AFFORDABILITY.

The use of the HJ-BIPLOT method developed by GALINDO (1986), an evolution of the classical BIPLOT introduced by GABRIEL $(1971,1981)$, allows a better simultaneous representation of the effects of political, economic and social decisions on the Eurozone countries, by identifying their similarities and dissimilarities concerning wealth, living standards and affordability.

Traditionally, descriptive statistics allow only an analysis of the average country on an individual level. On the other hand, the HJ-BIPLOT identifies relationships between the individuals (countries per year), between the variables and between individuals and variables, allowing the identification of hidden patterns in the data, facilitating and enriching the interpretation of the results.

Thus, we highlight four major objectives:

(1) To generate a methodological approach, with the use of the HJ-BIPLOT method in order to achieve a richer diagnosis, for the 2010-2014 period, of the effects of political, economic and social decisions on the twelve Eurozone Countries, by identifying their similarities and dissimilarities;

(2) To identify relationships between wealth, living standards and affordability in the housing situation in twelve Eurozone countries for the period 2010-2014;

(3) To recognize behavioural typologies in the twelve Eurozone countries linked to Wealth and Living Standards associated with Housing Affordability; 
(4) To distinguish clusters of countries with divergences and/or convergences in the housing sector.

\section{Methodology and data}

\subsection{BIPLOT methods}

BIPLOT analysis is a multivariate technique proposed by GABRIEL (1971) which has the main objective of performing an approximated graphical representation, with reduced dimension, of a data matrix $\mathrm{X}_{\mathrm{nxp}}$. It is done in such a way that the representation allows visualization in the same plane of the relations and interrelations between rows and columns of matrix X. According to GABRIEL (1971), "Every rank two matrix can be graphically represented by a BIPLOT that consists of a vector for each line and a vector for each column, chosen so that each element of the matrix is exactly these vectors' internal product. If the matrix has a rank greater than two, this matrix can be represented in an approximated way, by a BIPLOT of a matrix of rank two."

The original data matrix $\mathrm{X}$ is to be represented as the product of two matrices performed by Singular Value Decomposition of the matrix in Singular Values SVD, which contains the row and column vectors and which constitutes the elements considered in the graphical representation.

In the BIPLOT representation of $X_{\mathrm{nxp}}$, there are simultaneously two sets of vectors $a_{1}, a_{2}, \ldots . ., a_{n}$ for the lines from $X$, representing the individuals (observations of countries for years), and $b_{1}, b_{2}, \ldots \ldots, b_{p}$ for the columns of $X$, representing the variables, in such a way that the internal product $a_{i}{ }^{T} b_{j}$, approximated to element $\mathrm{x}_{\mathrm{ij}}$ of the original matrix, is as good as possible.

If the rank of matrix $X_{n x p}(r=\min (n, p))$ is greater than three, the BIPLOT representation will always be a data approximation. Nonetheless, when the rank of $\mathrm{X}_{\mathrm{nxp}}$ is two or three, the representation of the data in bifactorial or trifactorial planes is exact.

BIPLOT methods are used as a data visualization tool essentially due to two properties: the internal product property, which originates an exact or 
approximated representation of the individuals in space, and the property of equality between the cosine of the angle formed by the vectors which represent two variables and the correlation coefficient between these same variables. The properties of BIPLOT are detailed in GABRIEL (1971).

As result of the BIPLOT properties it is possible to identify:

1) The relations between column vectors (individuals);

2) The relations between line vectors (variables);

3) The interrelations between line vectors and column factors.

Therefore the BIPLOT representation gives a more complete picture of the data matrix than any scatter plot. Also the identification of the relations and interrelations of individuals and variables is of value, as it facilitates multivariate analysis of data. The seminal works in BIPLOT Methods, known as Classical BIPLOTS, were developed by GABRIEL $(1971,1981)$ and are designated JKBIPLOT, GH-BIPLOT and SQRT-BIPLOT.

An HJ-BIPLOT (GALINDO, 1986) for a data matrix $X_{n x p}$ is defined as the multivariate graphical representation by means of vectors $j_{1}, j_{2}, \ldots, j_{n}$ for the lines (individuals) and $\mathrm{h}_{1}, \mathrm{~h}_{2}, \ldots, \mathrm{h}_{\mathrm{p}}$ for the columns of $\mathrm{X}$, selected so that row and column representations can be projected in the same reference system with the same maximum quality of representation. The rows are represented by points and the columns by vectors. The advantages and properties of BIPLOT (GABRIEL, 1971) apply to the HJ-BIPLOT developed by GALINDO (1986).

\subsection{Ward's method}

The general principle of classification used in this research is based on building a table of similarities between the series data. For this purpose, Ward's method was used (WARD, 1963), considering the Euclidean distance for hierarchical clustering. In Ward's method, the total variance is equal to the sum of the internal variance of the class and inter-class variance. It is therefore necessary to find a homogeneity within each class (thus minimizing the variation of inter-class variance), and a heterogeneity between classes. Thus, at each step of the computation, the algorithm either clusters or combines observations, minimizing 
the results of error from the squares or alternatively maximizing the determination coefficient value, in order to maximize the similarity within the groups and differences between groups.

\subsection{The individuals - observations}

The observations used in this research comprise the first twelve countries of the Eurozone which first used the euro currency, for the period of 2010-2014. The sample countries are presented in Table 1.

Table 1. 12 Euro Area countries

\begin{tabular}{lc}
\hline COUNTRIES & COD \\
\hline Austria & AT \\
Belgium & BE \\
Finland & FI \\
France & FR \\
Germany & DE \\
Greece & EL \\
Ireland & IE \\
Italy & IT \\
Luxembourg & LU \\
Netherlands & NL \\
Portugal & PT \\
Spain & ES \\
\hline
\end{tabular}

Source: own elaboration

\subsection{The variables}

The variables used in this research are indicators collected from EUROSTAT databases and are of various types: economic, housing stock, affordability and quality. The variables used in this investigation are presented in Table 2 . We consider them appropriate to study the effects of political, economic and social decisions on the housing problem in Eurozone countries, identifying their similarities and dissimilarities, for the period 2010-2014. 
Table 2. 10 indicators

\begin{tabular}{|c|c|c|c|}
\hline TYPE & COD & DESIGNATION & $\begin{array}{l}\text { EUROSTAT } \\
\text { database }\end{array}$ \\
\hline General Economic Indicator & GDPPC & GDP per capita & nama_10_pc \\
\hline General Economic Indicator & UNP & Unemployment rate - annual average (\%) & une_rt_a \\
\hline Housing Stock Indicator & OML & Owner with mortage or loan $(\%)$ & ilc_lvho02 \\
\hline Housing Stock Indicator & TEN & Tennant & ilc_lvho02 \\
\hline Housing Affordability Indicator & SHCI & Share of housing cost in disposable income (\%) & ilc_mded01 \\
\hline Housing Affordability Indicator & OBD & $\begin{array}{l}\text { Housing cost overburden rate (as \% of } \\
\text { population) }\end{array}$ & ilc_lvho07a \\
\hline Housing Affordability Indicator & $\begin{array}{l}\text { HWEG } \\
\text { FI }\end{array}$ & $\begin{array}{l}\text { Annual average index-housing, water, electricity, } \\
\text { gas and other fuels }\end{array}$ & prc_hicp_aind \\
\hline Housing Affordability Indicator & HPI & House prices index & tipsho20 \\
\hline $\begin{array}{l}\text { Population and Social } \\
\text { Condition }\end{array}$ & RPSE & Population at risk of poverty (\%) & ilc_peps01 \\
\hline Housing Quality Indicator & OCD & Housing overcrowding rate & ilc_lvho05a \\
\hline
\end{tabular}

\subsection{The methodological procedure}

The methodological options used in this research are presented in Table 3.

Table 3. BIPLOT and Segmentation procedure by MultBiplot (2015)

\begin{tabular}{ll}
\hline Type of BIPLOT & HJ-BIPLOT \\
\hline Transformation of the raw data & $\begin{array}{l}\text { Column Standardization (z-s cores) } \\
\text { Estimation Method }\end{array}$ \\
$\begin{array}{l}\text { Singular Value Decomposition } \\
\text { Segmentation Process }\end{array}$ & $\begin{array}{l}\text { Hierarchical Cluster with the Euclidean distance using } \\
\text { the HJ-BIPLOT scores - Ward's Method }\end{array}$ \\
\hline & Source: own compilation
\end{tabular}

The statistical software used for the data treatment was MultBiplot, version 15.1412 (VILLARDON, 2015).

\section{Results}

Table 4 (see APPENDIX) presents the EUROSTAT database, for the period 2010-2014, used for the production of the results that support this research.

Through the application of HJ-BIPLOT with the MultBiplot software, we were able to attain a two-dimensional solution that captured about $63 \%$ of the variability of the original data, with $44.71 \%$ of the information retained on the first axis (Table 5). 
Table 5. Explanation level of Inertia

\begin{tabular}{cccc}
\hline A xis & Eigenvalue & $\begin{array}{c}\text { Inertia } \\
\text { Explained Variance }\end{array}$ & Accumulated Interia \\
\hline 1 & 268286 & 44714 & 44714 \\
2 & 109209 & 18201 & 62916 \\
3 & 90118 & 15.02 & 77935 \\
\hline \multicolumn{3}{c}{ Source: MultBiplot (2015) output }
\end{tabular}

In Table 6 (see APPENDIX), we observe the relative contributions of the 12 Eurozone countries (2010-2014), distributed in three dimensions, where the most significant contributions for the construction of the factorial axes can be distinguished. Table 6 (see APPENDIX) also shows the factorial coordinates of the 60 observations that allow a projection in Euclidean space (Figure 1) of the 12 Eurozone countries for the period 2010-2014. Thus a cloud of observations can be observed spread over the four quadrants of this factorial structure.

Also from Figure 1 and according to the most relevant contributions, it becomes possible to interpret the trajectories of the countries linked to the two axes (Table 7).

Table 7. Contributions interpretation (rows)

\begin{tabular}{|c|c|c|}
\hline \multirow{9}{*}{ Axis1 $(73 \%)$} & EL (2010-2014) & Declining \\
\hline & LU (2010-2014) & \\
\hline & FI (2010-2014) & Stable \\
\hline & FR (2011-2013) & \\
\hline & ES (2012-2014) & \\
\hline & BE (2010-2011) & \\
\hline & IT (2013-2014) & \\
\hline & PT (2014) & \\
\hline & AT (2012) & \\
\hline \multirow{5}{*}{ Axis2 $(74 \%)$} & DE (2010-2014) & Declining \\
\hline & IE (2010-2014) & Stable \\
\hline & PT (2010-2013) & \\
\hline & ES (2010-2011) & \\
\hline & AT (2013-2014) & \\
\hline
\end{tabular}

Thus, the full paths of EL, LU and FI with the incomplete trajectories of FR, ES, BE, IT, PT and AT contribute $73 \%$ to the total explicability of the first axis. Also, 


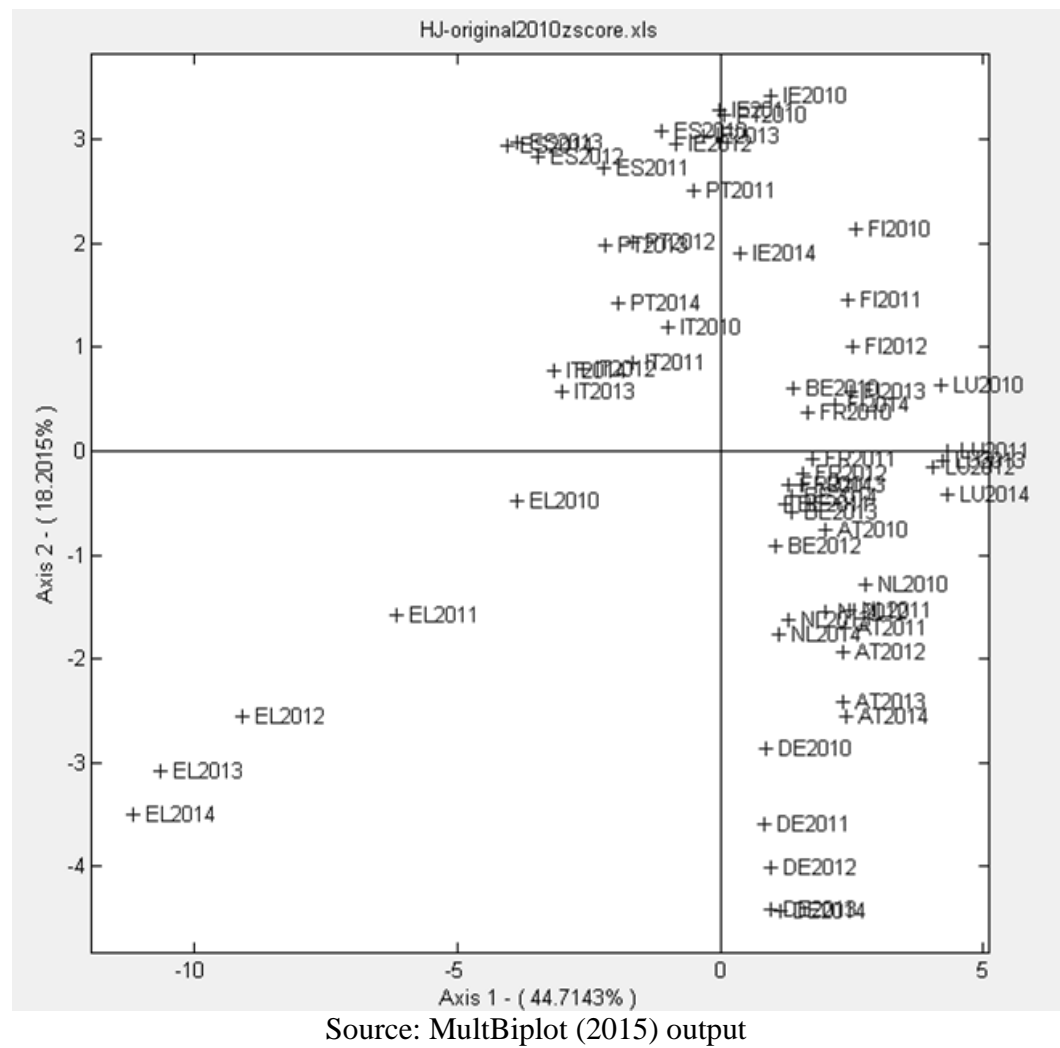

Figure 1. HJ-BIPLOT factorial representation of plane 1-2 for the countries (2010-2014)

with the spatial positioning, we can see a downward trend in EL and a stable one in LU and FI. Similarly, a downward trend is observed in the full path of DE and a stable trend in IE which, together with incomplete trajectories of PT, ES and AT, contribute $74 \%$ to the explicability of the second axis. These detected behaviours can be seen in Figure 2.

On the other hand, Table 8 describes the relative contributions of the 10 indicators, distributed in three dimensions where the most significant contributions to the construction of the factorial axes can be distinguished. Table 8 also shows the factorial coordinates of the variables (vectors) that allow a projection in the same Euclidean space (Figure 3) of the 10 indicators also spread over the four quadrants of the HJ-BIPLOT structure. 


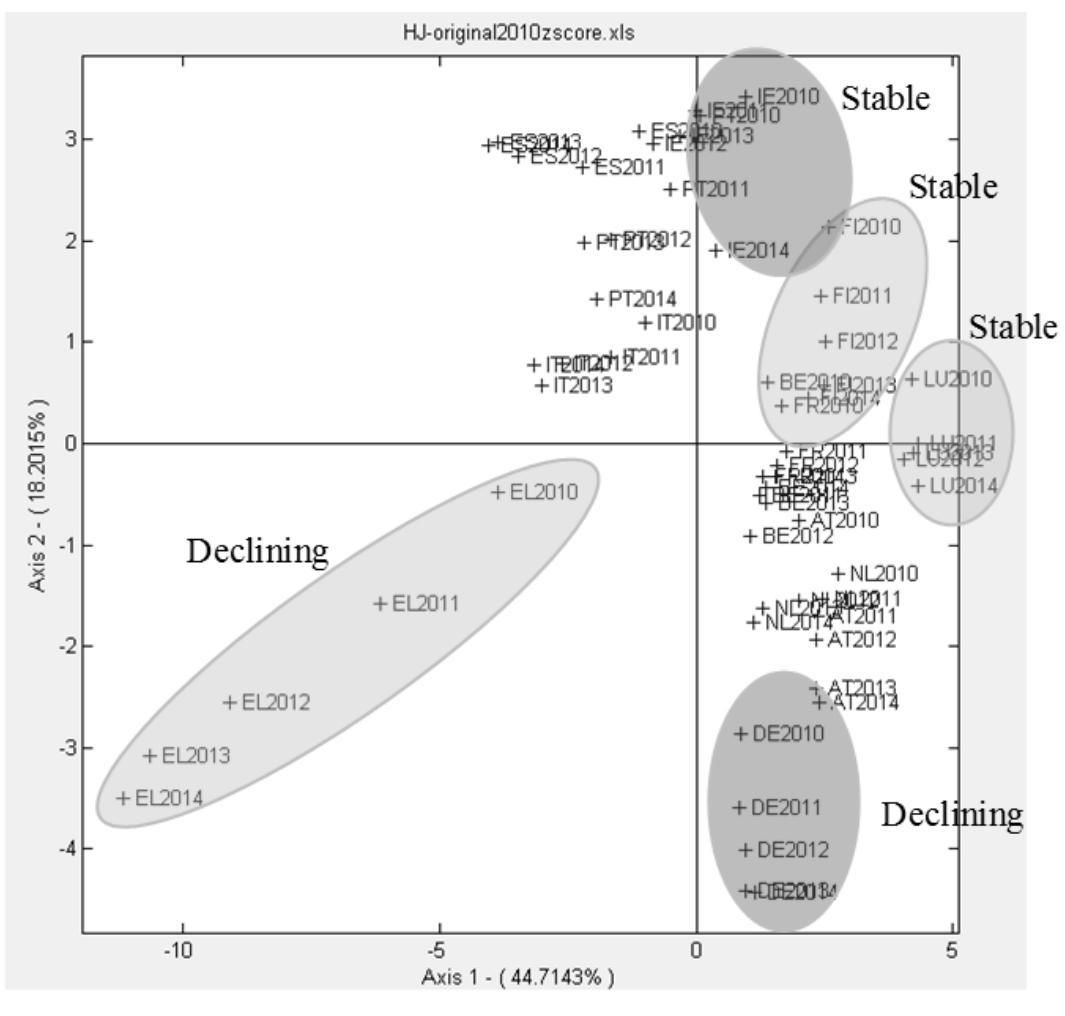

Source: MultBiplot (2015) output

Figure 2. Interpretation of detected trajectories

Table 8. HJ-BIPLOT columns relative contributions and coordinates

\begin{tabular}{lcccccc}
\hline & \multicolumn{2}{c}{ Relative Contributions (Columns) } & \multicolumn{3}{c}{ Coordinates (Columns) } \\
\cline { 2 - 7 } & Axis1 & Axis2 & Axis3 & Axis1 & Axis2 & Axis3 \\
\hline OML & 362 & 12 & 569 & 4.66 & 0.84 & 5.842 \\
TEM & 192 & 443 & 72 & 3.392 & -5.153 & -2.081 \\
UNP & 738 & 127 & 34 & -6.655 & 2.765 & 1.434 \\
OCD & 422 & 34 & 356 & -5.033 & -1.428 & -4.62 \\
OBD & 559 & 312 & 75 & -5.794 & -4.326 & 2.12 \\
SHCI & 323 & 445 & 129 & -4.405 & -5.167 & 2.78 \\
GDPPC & 450 & 11 & 14 & 5.198 & -0.804 & 0.926 \\
HWEGFI & 144 & 232 & 71 & -2.943 & -3.732 & 2.059 \\
RPSE & 777 & 76 & 27 & -6.827 & 2.135 & -1.271 \\
HPI & 503 & 129 & 155 & 5.494 & -2.779 & -3.054 \\
\hline & \multicolumn{7}{c}{ Source: MultBiplot (2015) output } & &
\end{tabular}




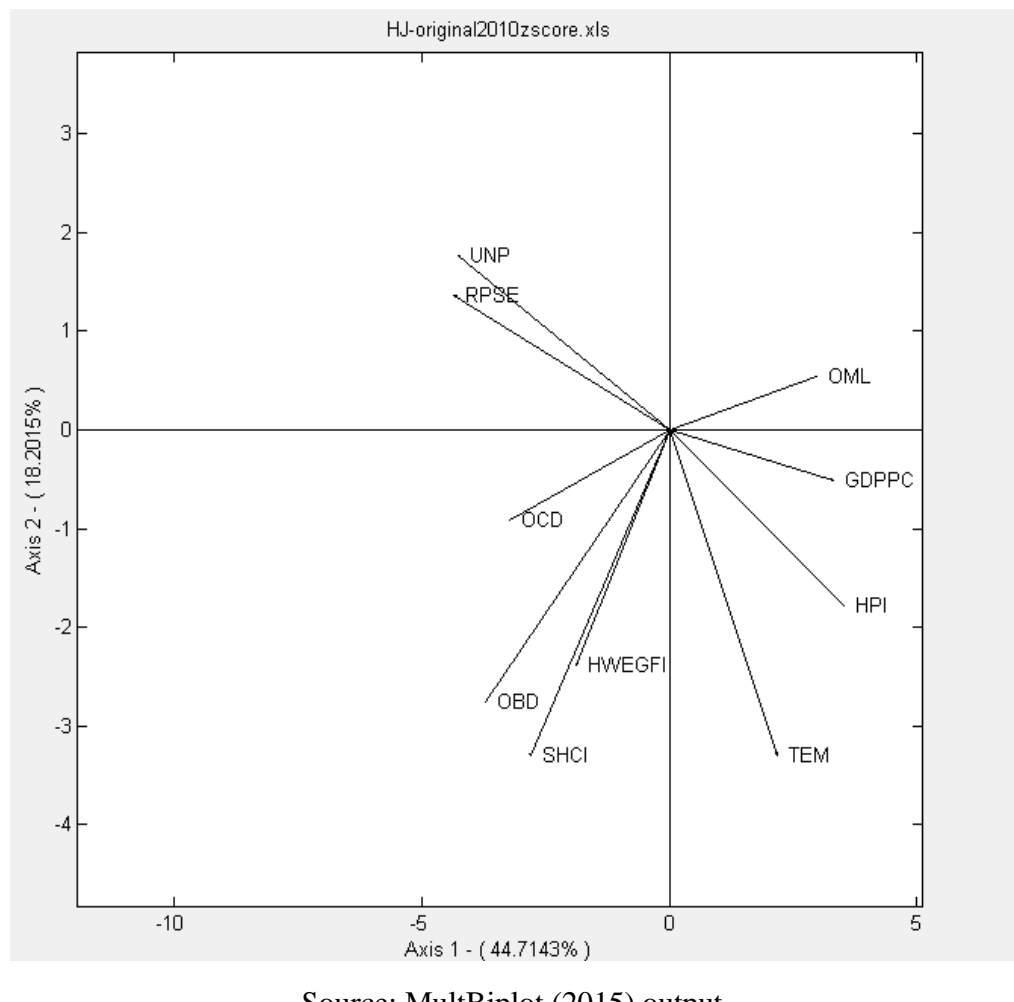

Source: MultBiplot (2015) output

Figure 3. HJ-BIPLOT factorial representation of plane 1-2 for the indicators (2010-2014)

In Figure 3, the higher the norm of the vector, the greater the variability associated with the represented variable. For example, the SHCI and TEN variables show greater variability between the countries for the different years under review. Also from Figure 3 and according to the most relevant contributions, it becomes possible in Table 9 to interpret the correlations of the indicators between each other and associated with the two axes (by means of the angles which they form between themselves and with the two axes). Thus, the proximity (the smaller the angle, the higher the correlation) of RPSE, UNP and OCD, which we interpret as Life Standard, together with the proximity of HPI and GDPPC, which we interpret as Wealth Standard, contribute $65 \%$ to the total explicability of the first axis, which we globally designate LIFE \& WEALTH STANDARDS. In turn, the proximity of SHCI, OBD and HWEGFI, which we interpret as Affordability, 
together with TEN, contribute $79 \%$ to the explicability of the second axis, which we globally call AFFORDABILITY.

Table 9. Contributions interpretation (columns)

\begin{tabular}{|c|c|c|c|c|}
\hline \multirow{5}{*}{$\begin{array}{l}\text { Axis } 1 \\
(65 \%)\end{array}$} & RPSE & Population at risk of poverty (\%) & & \multirow{5}{*}{$\begin{array}{c}\text { LIFE \& } \\
\text { WEALTH } \\
\text { STANDARDS }\end{array}$} \\
\hline & UNP & Unemployment rate - annual average (\%) & Life Standard & \\
\hline & OCD & Housing overcrowding rate & & \\
\hline & HPI & House prices index & \multirow{2}{*}{$\begin{array}{l}\text { Wealth } \\
\text { Standard }\end{array}$} & \\
\hline & GDPPC & GDP per capita & & \\
\hline \multirow{4}{*}{$\begin{array}{l}\text { Axis2 } \\
(79 \%)\end{array}$} & SHCI & Share of housing cost in disposable income $(\%)$ & & \multirow{4}{*}{$\begin{array}{l}\text { AFFORDA- } \\
\text { BILITY }\end{array}$} \\
\hline & OBD & $\begin{array}{l}\text { Housing cost overburden rate (as \% of } \\
\text { population) }\end{array}$ & Affordability & \\
\hline & HWEGFI & $\begin{array}{l}\text { Annual average index-housing, water, electricity, } \\
\text { gas and other fuels }\end{array}$ & & \\
\hline & TEN & Tennant & Tennant & \\
\hline
\end{tabular}

Source: own elaboration

These detected patterns can be seen in Figure 4.

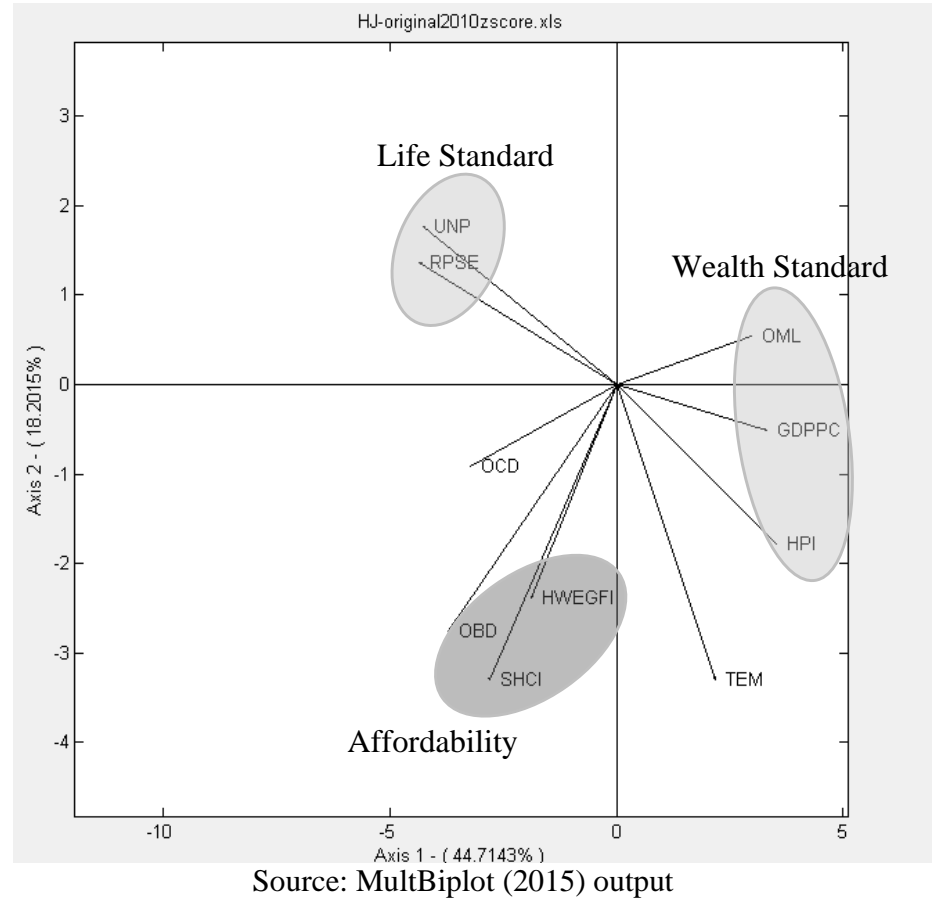

Figure 4. Interpretation of detected patterns 
Nevertheless, it is interesting to note that Life Standard is, on the one hand, negatively correlated with Wealth Standard (except OML, which has no significate correlation) but, on the other hand, shows almost no correlation with Affordability. It is also interesting to note that Wealth Standard is negatively correlated with Affordability (except HPI, which has a slightly positive correlation).

Figure 5 is an HJ-BIPLOT simultaneous representation of the observations and the variables, where three clusters of countries can be detected by a hierarchical segmentation process using Ward's method on the HJ-BIPLOT coordinates.

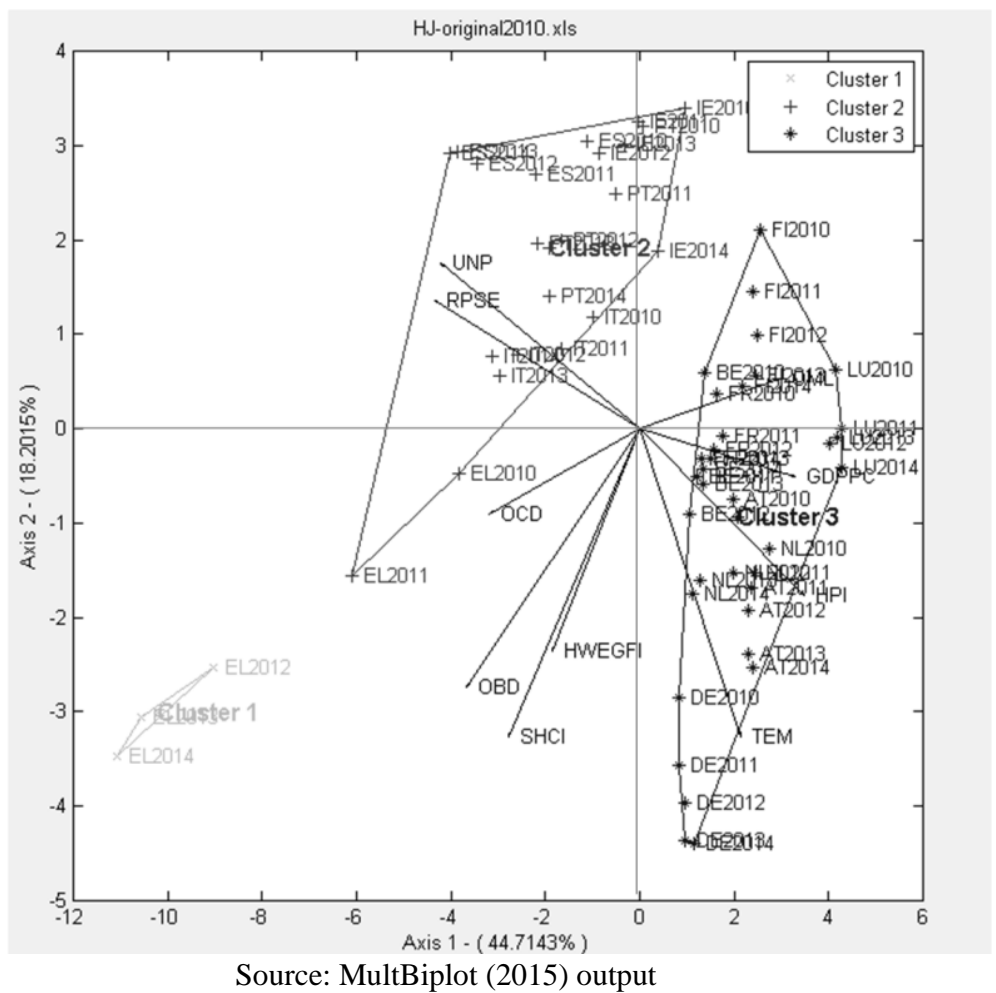

Figure 5. HJ-BIPLOT simultaneous factorial representation of plane 1-2 and 3 clusters of countries (2010-2014) 
Independently of the clusters found, the countries closest to the vectors are more related to the variables that these same vectors represent. Through the projection of the countries on the vectors (variables) we can identify which countries/years contributed most to the value of the variable. For example, Luxembourg (LU), for any of the years in question, was the greatest contributor to GDPPC. This finding is consistent with what we know about Luxembourg, which is the country with the highest GDP per capita in the Eurozone. Table 10 shows the formation of three clusters of countries associated with the period 2010-2014.

Table 10. Composition of clusters according to Ward's method

\begin{tabular}{clllll}
\hline Cluster 1 & \multicolumn{2}{c}{ Cluster 2 } & & Cluster 3 & \\
\cline { 1 - 5 } EL2012 & EL2010 & IE2014 & AT2010 & DE2012 & FR2014 \\
EL2013 & EL2011 & IT2010 & AT2011 & DE2013 & LU2010 \\
EL2014 & ES2010 & IT2011 & AT2012 & DE2014 & LU2011 \\
\cline { 1 - 5 } & ES2011 & IT2012 & AT2013 & FI2010 & LU2012 \\
& ES2012 & IT2013 & AT2014 & FI2011 & LU2013 \\
& ES2013 & IT2014 & BE2010 & FI2012 & LU2014 \\
& ES2014 & PT2010 & BE2011 & FI2013 & NL2010 \\
& IE2010 & PT2011 & BE2012 & FI2014 & NL2011 \\
& IE2011 & PT2012 & BE2013 & FR2010 & NL2012 \\
& IE2012 & PT2013 & BE2014 & FR2011 & NL2013 \\
& IE2013 & PT2014 & DE2010 & FR2012 & NL2014 \\
\cline { 2 - 5 } & & & DE2011 & FR2013 & \\
\cline { 3 - 6 } & & Source: own elaboration & &
\end{tabular}

It can be observed that countries in Clusters 2 or 3 generally maintain their affiliation throughout the study period. However, it is interesting to note that Greece (EL) belonged to Cluster 2 in 2010 and 2011 and joined Cluster 1 in 2012, 2013 and 2014. There was certainly a change in Greece's performance at the end of the period.

\section{Discussion}

In short, Figure 6 shows three behavioural typologies related to the performance of 12 Eurozone countries with regard to the effects of housing policy options, for the period 2010-2014. 


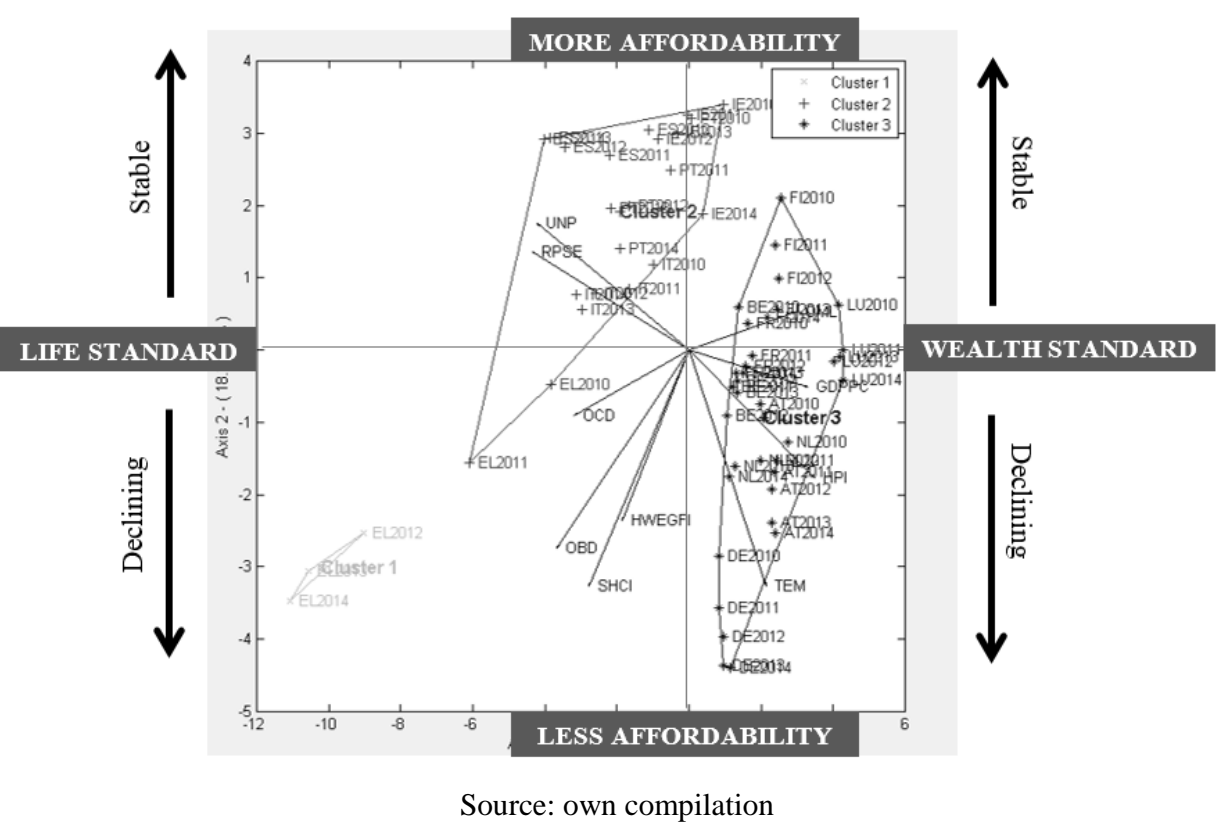

Figure 6. Behavioural typologies

In Cluster 1 (third quadrant), it is observed that Greece revealed a decreasing performance in 2012, 2013 and 2014 concerning LIFE STANDARD associated with LESS AFFORDABILITY. In this period, Greece was subjected to measures related to the $\mathrm{BCE} / \mathrm{IMF} / \mathrm{EU}$ intervention that resulted in a negative outcome in these areas.

In Cluster 2 (second quadrant), a stable performance can be detected, except for Greece in 2010 and 2011, mostly concerning LIFE STANDARD associated with MORE AFFORDABILITY. Therefore, the countries characterized by this cluster in this time period were relatively unaffected and maintained their positioning.

In Cluster 3 (first and fourth quadrants), a stable performance can be perceived concerning WEALTH STANDARD, mostly for Finland and Luxembourg, associated with MORE AFFORDABILITY. On the other hand, for all of the other countries, there was a decreasing performance concerning 
WEALTH STANDARD related to LESS AFFORDABILITY. A specificity of behaviour can be observed in the case of Finland and Luxembourg, which were able to maintain their levels of wealth and increase affordability; nonetheless, the other countries show a downward trend in the same aspects.

\section{Conclusions}

Thus, we conclude:

1. The ten selected socio-economic indicators highlighted relationships between wealth, living standards and affordability in the housing situation.

2. There are two main housing problem realities in the Eurozone linked to Wealth and Living Standards associated with Housing Affordability.

3. There are three behavioural typologies of countries, although some particularities are associated with some cluster members.

4. Greece has an untypical performance compared with the other countries.

5. The methodological approach with the use of the HJ-BIPLOT method produced a richer diagnosis, for the 2010-2014 period, of the effects of political, economic and social decisions on the twelve Eurozone countries, by identifying their similarities and dissimilarities.

This study can be seen as a contribution to the future application of multivariate data methods in housing research. Even from an exploratory perspective, it is a potential tool for producing richer information not only for academia but also for policy makers.

\section{Acknowledgements}

The authors would like to acknowledge the CIEO Research Centre for Spatial and Organizational Dynamics, the Autónoma University of Lisbon and the University of Algarve for having provided the conditions to publish this work.

This paper is financed by National Funds provided by the FCT Foundation for Science and Technology through project UID/SOC/04020/2013. 


\section{REFERENCES}

Andrews D., A. Caldera Sánchez, A. Johansson (2011): Housing Markets and Structural Policies in OECD Countries, OECD Economics Department Working Papers, No. 836, OECD Publishing.

Arestis Philip, González Ana Rosa (2013): Modelling the Housing Market in OECD Countries, Levy Economics Institute of Bard College, Working Paper No. 764, May.

Dewilde C., De Decker (2016): Changing Inequalities in Housing Outcomes across Western Europe, Housing, Theory and Society, Vol. 33, Issue 2, pp.121-161.

Dewilde Caroline (2015): Housing Regimes and Housing Outcomes in Europe, HOWCOME Working Paper Series, No. 10.

EUROSTAT (2014): Living conditions in Europe, The Eurostat Statistical books, Publications Office of the European Union, Luxembourg.

EUROSTAT (2015): http://ec.europa.eu/eurostat/data/database

Gabriel K.R. (1971): The BIPLOT display of matrices with application to principal components analysis. Biometrika, 58: 453-467.

Gabriel K.R. (1981): Biplot display of multivariate matrices for inspection of data and diagnosis. in Interpreting Multivariate Data (ed. V. Barnett), pp. 147-173. New York: Wiley

Galindo M.P. (1986): Una alternativa de representación simultánea: HJ-BIPLOT. Questíio, 10 (1): 13-23.

Haffner Marietta, Heylen Kristof (2011): User Costs and Housing Expenses. Towards a more Comprehensive Approach to Affordability. Housing Studies, Vol. 26, No. 4, pp. 593-614.

Martin Ron (2011): The local geographies of the financial crisis: from housing bubble to economic recession and beyond. Journal of Economic Geography, 11: 587-618.

Newman S.J., Basgal O., Nightingale D.S. (2000): Welfare Reform: Should Housing Have a Role? In Journal of Housing and Community Development. Vol. 57; Issue 1; Jan/Feb, pp. 15-24.

Santos António Duarte (2014): As politicas públicas de habitação em Portugal: avaliação longitudinal da promoção imobiliária, Tese de Doutoramento em Economia, Universidade Autónoma de Lisboa.

Ward J.H. (1963): Hierarchical grouping to optimize an objective function, Journal of the American Statistical Association, 58, 236-244.

Villardón J.L. (2015): MULTBIPLOT: A package for Multivariate Analysis using Biplots. Departamento de Estadística. Universidad de Salamanca. http://biplot.usal.es/ ClassicalBiplot/index.html 


\section{APPENDIX}

Table 4. EUROSTAT database for the period 2010-2014

\begin{tabular}{|c|c|c|c|c|c|c|c|c|c|c|}
\hline & OML & TEN & UNP & OCD & OBD & SHCI & GDPPC & HWEGFI & RPSE & HPI \\
\hline AT2010 & 25 & 42.6 & 4.8 & 12 & 6.5 & 18.6 & 35200 & 88.26 & 18.9 & 100 \\
\hline BE2010 & 41.7 & 28.4 & 8.3 & 4.2 & 8.9 & 20.5 & 33500 & 92.62 & 20.8 & 100 \\
\hline FI2010 & 42 & 25.7 & 8.4 & 6.1 & 4.2 & 17.6 & 34900 & 83.86 & 16.9 & 100 \\
\hline FR2010 & 29 & 38 & 9.3 & 9.2 & 5.1 & 17.8 & 30800 & 88.46 & 19.2 & 100 \\
\hline DE2010 & 27.8 & 46.8 & 7 & 7.1 & 14.5 & 27.5 & 32100 & 91.7 & 19.7 & 100 \\
\hline EL2010 & 17.5 & 22.8 & 12.7 & 25.5 & 18.1 & 29 & 20300 & 90.33 & 27.7 & 100 \\
\hline IE2010 & 34.5 & 26.7 & 13.9 & 3.4 & 4.9 & 16.2 & 36400 & 80 & 27.3 & 100 \\
\hline IT2010 & 15.8 & 27.4 & 8.4 & 24.3 & 7.7 & 16.7 & 26800 & 87.7 & 25 & 100 \\
\hline LU2010 & 39.4 & 31.9 & 4.6 & 7.8 & 4.7 & 13.8 & 77900 & 91.28 & 17.1 & 100 \\
\hline NL2010 & 59.5 & 32.8 & 5 & 2 & 14 & 28.6 & 38000 & 89.21 & 15.1 & 100 \\
\hline PT2010 & 32.5 & 25.1 & 12 & 14.6 & 4.2 & 14.3 & 17000 & 82.4 & 25.3 & 100 \\
\hline ES2010 & 34.4 & 20.2 & 19.9 & 5 & 9.7 & 17.7 & 23200 & 88.94 & 26.1 & 100 \\
\hline AT2011 & 23 & 47.6 & 4.6 & 12.2 & 5.5 & 18.6 & 36800 & 91.45 & 19.2 & 106.3 \\
\hline BE2011 & 41.9 & 28.2 & 7.2 & 2.2 & 10.6 & 21.3 & 34500 & 101.03 & 21 & 104 \\
\hline FI2011 & 41.9 & 25.9 & 7.8 & 6.5 & 4.4 & 17.5 & 36500 & 89.85 & 17.9 & 103.2 \\
\hline FR2011 & 29.4 & 36.9 & 9.2 & 8 & 5.2 & 18.1 & 31500 & 92.4 & 19.3 & 105.8 \\
\hline DE2011 & 28.1 & 46.6 & 5.8 & 6.7 & 16.1 & 28.3 & 33700 & 95.4 & 19.9 & 103.5 \\
\hline EL2011 & 15.7 & 24.1 & 17.9 & 25.9 & 24.2 & 32.3 & 18600 & 98.83 & 31 & 94.5 \\
\hline IE2011 & 34.6 & 29.8 & 14.7 & 2.6 & 6.1 & 17.3 & 38000 & 82.9 & 29.4 & 86.1 \\
\hline IT2011 & 15.6 & 26.8 & 8.4 & 24.5 & 8.7 & 17.2 & 27300 & 92.2 & 28.1 & 100.7 \\
\hline LU2011 & 40 & 31.8 & 4.8 & 6.8 & 4.2 & 13.8 & 81300 & 97.59 & 16.8 & 103.7 \\
\hline NL2011 & 59.6 & 32.9 & 5 & 1.7 & 14.5 & 29.1 & 38500 & 92.02 & 15.7 & 98 \\
\hline PT2011 & 34 & 25 & 12.9 & 11 & 7.2 & 16.7 & 16700 & 87.88 & 24.4 & 95.1 \\
\hline ES2011 & 32 & 20.3 & 21.4 & 6.6 & 10 & 18.4 & 22900 & 95.31 & 26.7 & 92.4 \\
\hline AT2012 & 26.4 & 42.5 & 4.9 & 13.9 & 7 & 18.9 & 37600 & 94.66 & 18.5 & 114 \\
\hline BE2012 & 43.2 & 27.6 & 7.6 & 1.6 & 11 & 22 & 35000 & 105.05 & 21.6 & 106.4 \\
\hline FI2012 & 42.2 & 26.1 & 7.7 & 6 & 4.5 & 17.9 & 36900 & 92.74 & 17.2 & 105.7 \\
\hline FR2012 & 29.9 & 36.3 & 9.8 & 8.1 & 5.2 & 17.9 & 31800 & 95.54 & 19.1 & 105.2 \\
\hline DE2012 & 28 & 46.7 & 5.4 & 6.6 & 16.6 & 27.9 & 34300 & 98.1 & 19.6 & 107.1 \\
\hline EL2012 & 15.2 & 24.1 & 24.5 & 26.5 & 33.1 & 37 & 17300 & 106.12 & 34.6 & 83.5 \\
\hline IE2012 & 34.9 & 30.4 & 14.7 & 3.2 & 6.6 & 19 & 38100 & 87.2 & 30 & 76.3 \\
\hline IT2012 & 16.1 & 25.8 & 10.7 & 26.1 & 8.1 & 16.8 & 26700 & 98.8 & 29.9 & 97.9 \\
\hline LU2012 & 42.6 & 29.2 & 5.1 & 7 & 4.9 & 14 & 82000 & 101.25 & 18.4 & 108 \\
\hline NL2012 & 59.9 & 32.5 & 5.8 & 2.5 & 14.4 & 29.2 & 38500 & 95.03 & 15 & 91.5 \\
\hline PT2012 & 33.8 & 25.5 & 15.8 & 10.1 & 8.3 & 18.2 & 16000 & 95.55 & 25.3 & 88.4 \\
\hline ES2012 & 31.8 & 21.1 & 24.8 & 5.6 & 10.7 & 19.1 & 22300 & 100.07 & 27.2 & 78.7 \\
\hline AT2013 & 26.4 & 42.7 & 5.4 & 14.7 & 7.2 & 19.2 & 38100 & 97.17 & 18.8 & 119.9 \\
\hline BE2013 & 42.9 & 27.7 & 8.4 & 2 & 9.6 & 20.8 & 35400 & 103.65 & 20.8 & 107.6 \\
\hline FI2013 & 42.6 & 26.4 & 8.2 & 6.9 & 4.9 & 18.2 & 37400 & 95.44 & 16 & 106.9 \\
\hline FR2013 & 31.8 & 35.7 & 10.3 & 7.4 & 5.2 & 18.2 & 32100 & 97.88 & 18.1 & 103.2 \\
\hline DE2013 & 27.6 & 47.4 & 5.2 & 6.7 & 16.4 & 28.2 & 35000 & 100.5 & 20.3 & 110.4 \\
\hline EL2013 & 15.6 & 24.2 & 27.5 & 27.3 & 36.9 & 39.9 & 16500 & 110.74 & 35.7 & 74.5 \\
\hline IE2013 & 35.5 & 30.1 & 13.1 & 2.8 & 4.9 & 15.7 & 39000 & 90.7 & 29.5 & 77.8 \\
\hline IT2013 & 17.2 & 26.7 & 12.1 & 27.1 & 8.9 & 17.4 & 26500 & 100.8 & 28.5 & 92.3 \\
\hline LU2013 & 45.6 & 27 & 5.9 & 6.2 & 5.6 & 13.8 & 85300 & 101.87 & 19 & 113.4 \\
\hline NL2013 & 60 & 32.9 & 7.3 & 2.6 & 15.7 & 29.5 & 38700 & 97.5 & 15.9 & 86 \\
\hline PT2013 & 34.6 & 25.8 & 16.4 & 11.4 & 8.3 & 18.3 & 16300 & 97.6 & 27.5 & 86.7 \\
\hline ES2013 & 32 & 22.3 & 26.1 & 5.2 & 10.3 & 19.5 & 22100 & 101 & 27.3 & 71.5 \\
\hline AT2014 & 25.3 & 42.8 & 5.6 & 15.3 & 6.6 & 18.3 & 38500 & 98.83 & 19.2 & 124.1 \\
\hline BE2014 & 42.9 & 28 & 8.5 & 2 & 10.4 & 20.8 & 35900 & 101.23 & 21.2 & 107.1 \\
\hline FI2014 & 43 & 26.8 & 8.7 & 7 & 5.1 & 18 & 37600 & 97.77 & 17.3 & 106.5 \\
\hline FR2014 & 31.3 & 35 & 10.3 & 7.1 & 5.1 & 18.3 & 32200 & 99.59 & 18.5 & 101.6 \\
\hline DE2014 & 26.6 & 47.5 & 5 & 6.6 & 15.9 & 27.3 & 36000 & 101.1 & 20.6 & 113.2 \\
\hline EL2014 & 13.3 & 26 & 26.5 & 27.4 & 40.7 & 42.5 & 16200 & 107.54 & 36 & 68.9 \\
\hline IE2014 & 34.8 & 31.4 & 11.3 & 3.6 & 5.5 & 15.4 & 41000 & 94.8 & 27.4 & 87.9 \\
\hline IT2014 & 17.3 & 26.9 & 12.7 & 27.2 & 8.5 & 17.1 & 26500 & 100.8 & 28.3 & 88.3 \\
\hline LU2014 & 42.5 & 27.5 & 6 & 6.7 & 6.8 & 14 & 87600 & 100.89 & 19 & 118.4 \\
\hline NL2014 & 59.2 & 33 & $\begin{array}{ll}7.4 \\
\end{array}$ & 3.5 & 15.4 & 29.4 & 39300 & 99.29 & 16.5 & 86.7 \\
\hline PT2014 & 35.5 & 25.1 & 14.1 & 10.3 & 9.2 & 19.3 & 16700 & 99.77 & 27.5 & 90.4 \\
\hline ES2014 & 32.1 & 21.2 & 24.5 & 5.3 & 10.9 & 19.1 & 22400 & 102.34 & 29.2 & 71.8 \\
\hline
\end{tabular}


Table 6. HJ-BIPLOT rows relative contributions and coordinates

\begin{tabular}{|c|c|c|c|c|c|c|}
\hline & \multicolumn{3}{|c|}{ Relative Contributions (Rows) } & \multicolumn{3}{|c|}{ Coordinates (Rows) } \\
\hline & Axis1 & Axis2 & Axis3 & Axis1 & Axis2 & Axis3 \\
\hline AT2010 & 264 & 37 & 363 & 1283 & -0.482 & -1505 \\
\hline BE2010 & 452 & 87 & 201 & 0.88 & 0.387 & 0.588 \\
\hline FI2010 & 389 & 265 & 1 & 1649 & 1361 & 0.098 \\
\hline FR2010 & 305 & 16 & 267 & 1057 & 0.24 & -0.989 \\
\hline DE2010 & 41 & 467 & 23 & 0.543 & -1834 & -0.405 \\
\hline EL2010 & 514 & 8 & 159 & -2464 & -0.307 & -1372 \\
\hline IE2010 & 42 & 522 & 22 & 0.619 & 2189 & -0.445 \\
\hline IT2010 & 49 & 68 & 722 & -0.646 & 0.758 & -2478 \\
\hline LU2010 & 614 & 14 & 0 & 2678 & 0.402 & -0.063 \\
\hline NL2010 & 273 & 59 & 355 & 1766 & -0.821 & 2014 \\
\hline PT2010 & 0 & 501 & 204 & 0.039 & 2073 & -1323 \\
\hline ES2010 & 77 & 577 & 10 & -0.719 & 1967 & 0.253 \\
\hline AT2011 & 265 & 137 & 397 & 1516 & -1092 & -1856 \\
\hline BE2011 & 209 & 36 & 314 & 0.79 & -0.327 & 0.969 \\
\hline FI2011 & 577 & 211 & 6 & 1544 & 0.933 & 0.156 \\
\hline FR2011 & 469 & 1 & 277 & 1127 & -0.048 & -0.867 \\
\hline DE2011 & 38 & 690 & 9 & 0.537 & -2298 & -0.266 \\
\hline EL2011 & 841 & 56 & 29 & -3927 & -1.01 & -0.723 \\
\hline IE2011 & 0 & 522 & 0 & -0.014 & 2098 & 0.053 \\
\hline IT2011 & 144 & 37 & 697 & -1076 & 0.542 & -2368 \\
\hline LU2011 & 586 & 0 & 2 & 2751 & 0.001 & 0.168 \\
\hline NL2011 & 228 & 90 & 453 & 1567 & -0.983 & 2211 \\
\hline PT2011 & 24 & 607 & 51 & -0.319 & 1606 & -0.464 \\
\hline ES2011 & 319 & 479 & 41 & -1.42 & 1741 & 0.508 \\
\hline AT2012 & 331 & 232 & 407 & 1482 & -1241 & -1643 \\
\hline BE2012 & 90 & 69 & 292 & 0.671 & -0.588 & 1207 \\
\hline FI2012 & 654 & 105 & 18 & 1609 & 0.644 & 0.267 \\
\hline FR2012 & 447 & 9 & 214 & 1003 & -0.14 & -0.694 \\
\hline DE2012 & 46 & 784 & 9 & 0.618 & -2564 & -0.273 \\
\hline EL2012 & 903 & 71 & 2 & -5817 & -1628 & 0.3 \\
\hline IE2012 & 36 & 434 & 31 & -0.546 & 1888 & 0.501 \\
\hline IT2012 & 294 & 27 & 482 & -1.67 & 0.502 & -2137 \\
\hline LU2012 & 484 & 1 & 10 & 2582 & -0.103 & 0.38 \\
\hline NL2012 & 149 & 91 & 582 & 1268 & -0.99 & 2503 \\
\hline PT2012 & 321 & 468 & 7 & -1064 & 1285 & 0.152 \\
\hline ES2012 & 438 & 293 & 125 & -2212 & 1.81 & 1182 \\
\hline AT2013 & 270 & 293 & 373 & 1482 & -1544 & -1741 \\
\hline BE2013 & 170 & 33 & 245 & 0.857 & -0.379 & 1029 \\
\hline FI2013 & 616 & 32 & 31 & 1586 & 0.362 & 0.355 \\
\hline FR2013 & 420 & 19 & 54 & 0.975 & -0.205 & -0.349 \\
\hline DE2013 & 39 & 819 & 12 & 0.617 & -2819 & -0.336 \\
\hline EL2013 & 890 & 74 & 17 & -6.81 & -1.97 & 0.953 \\
\hline
\end{tabular}

Source: MultBiplot (2015) output 